\title{
Análise da percepção ambiental acerca do bioma Caatinga por parte dos docentes de uma escola pública do município de Patos, Paraíba
}

\author{
Assessing the environmental perception of the biome Caatinga by teachers of a public \\ school in Patos County, Paraíba
}

\author{
SANTOS $^{1}$, J. O. dos; SANTOS, R. M. S. ${ }^{2}$; SANTOS SEGUNDO ${ }^{3}$, J. O.; SANTOS V. C. ${ }^{4}$ \\ joseozildo2014@outlook.com
}

\begin{abstract}
Resumo
A Caatinga nordestina apresenta-se em situação de vulnerabilidade. A exploração inadequada de seus recursos naturais e o superpastoreio têm contribuído para a diminuição da fauna original, ameaçando de extinção uma grande variedade de organismos. Levando em consideração o fato de que a Caatinga é o único bioma exclusivamente brasileiro, com biodiversidade composta por fauna e flora peculiar, mas que lamentavelmente é desvalorizada e pouco explorada cientificamente, como também marginalizada no processo educativo, este trabalho objetiva analisar a percepção ambiental dos docentes da Escola Estadual de Ensino Médio Monsenhor Vieira, localizada no município de Patos, Estado da Paraíba. Os dados coletados demonstram que uma grande parte dos professores entrevistados enfrentam dificuldades em contextualizar o ensino, no que diz respeito a focalizar o semiárido nas discussões promovidas no contexto escolar. E, como tal temática não é abordada de forma ampla, vem contribuindo para limitar o conhecimento sobre a região semiárida, apresentado pelos alunos na visão da maioria dos professores entrevistados.
\end{abstract}

Palavras-chave: Caatinga; Percepção Ambiental; Avaliação.

\begin{abstract}
The northeastern Caatinga presents itself in a vulnerable situation. Improper exploitation of its natural resources and overgrazing have contributed to the reduction of the original fauna, threatening to wipe out a large variety of organisms. Taking into consideration the fact that the Caatinga is the only exclusively Brazilian biome with biodiversity composed of fauna and unique flora, but that unfortunately is undervalued and little scientifically explored, but also marginalized in the educational process, this paper aims to analyze the environmental perception of teachers of the State Preparatory High School Monsignor Vieira, located in Patos county, State of Paraiba. The collected data show that a large part of the teachers interviewed face difficulties in contextualizing teaching, with regard to focus on the semi-arid region in the discussions held in the school context. And as such issue is not addressed broadly, it has contributed to limit the knowledge of the semiarid region, presented by the students in the vision of most teachers interviewed.
\end{abstract}

Keywords: Caatinga; Environmental awareness; Evaluation.

\section{INTRODUÇÃO}

A temática 'desequilíbrios ambientais' não é nova na história da civilização ocidental. Desde a Grécia antiga já se registrava uma preocupação com o uso do meio ambiente de forma desordenada e também em relação às suas consequências resultantes do mau uso dos recursos naturais. No que diz respeito ao semiárido brasileiro, a Caatinga tem se constituído um tema bastante discutido, principalmente, por ser considerada um dos biomas brasileiros mais degradado, tendo mais de $45 \%$ de sua cobertura original alterada pela ação do homem e também por localizarse em uma região conhecida como Polígono das Secas, onde se encontra ecossistemas mais vulneráveis ao processo de desertificação (CASTELLETTI et al., 2005).

\footnotetext{
${ }^{1}$ José Ozildo dos Santos, Centro de Desenvolvimento Sustentável do Semiárido, Universidade Federal de Campina Grande, Sumé $P B$, Brasil.

${ }^{2}$ Rosélia Maria de Sousa Santos, Programa de Pós-Graduação Stricto Sensu em Sistemas Agroindustriais - PPGSA, Universidade Federal de Campina Grande, Pombal-PB, Brasil.

${ }^{3}$ José Ozildo dos Santos Segundo, Centro de Educação (CE), Departamento de Fundamentos e Políticas da Educação (DFPE), Universidade Federal do Rio Grande do Norte (UFRN), Natal-RN, Brasil.

${ }^{4}$ Vanessa da Costa Santos, Programa de Pós-Graduação Stricto Sensu em Sistemas Agroindustriais - PPGSA, Universidade Federal de Campina Grande, Pombal-PB, Brasil.
} 
Um estudo desenvolvido por Araújo e Sousa (2011) abordando o estado de conservação da Caatinga nordestina, destaca que a situação atual apresentada por esse bioma é resultante de fatores favoráveis a situação de vulnerabilidade, das condições do clima, dos solos, com também da exploração inadequada dos recursos naturais e devido ao superpastoreio, o que tem contribuído para diminuição da fauna original, ameaçando de extinção uma grande variedade de organismos.

Quando se analisa os 'desequilíbrios ambientais' dessa região, dentre as maiores preocupações, pode-se destacar o processo de desertificação, que tem se intensificado pela ocupação e intervenção humana desordenada, provocando a perda de solos férteis, a extinção de várias espécimes da fauna e da flora, afetando a biodiversidade e a população humana (ABÍLIO; FLORENTINO, 2011).

Por outro lado, o Estado da Paraíba, onde o presente estudo foi realizado, é a unidade federativa que possui o maior percentual de área com nível de desertificação em nível muito grave, afetando o dia-a-dia de mais de 653 mil pessoas residentes em seu território (ABÍLIO; FLORENTINO, op. cit). É importante destacar que os problemas vivenciados nesse bioma são reflexos de uma longa ação predatória, que não tem levado em consideração os parâmetros de sustentabilidade, impossibilitando que o meio se recomponha de forma natural.

No que diz respeito à percepção ambiental, trata-se, segundo Silva; Cândido e Freire (2009, p. 24) de "um instrumento utilizado em diversas áreas do conhecimento, buscando a melhoria da qualidade de vida do homem e dos outros seres vivos, podendo ser definida como [...] o ato de perceber o ambiente no qual se está inserido, protegendo e cuidando do mesmo".

A partir do estudo da percepção ambiental é possível compreender as diferentes formas de ver e sentir o ambiente, possibilitando um maior envolvimento com as especificidades de cada comunidade, de maneira que possa ser desenvolvida uma educação ambiental participativa, capaz de valorizar o contexto ambiental, social, cultural, econômico e ético, elementos estes importantes para o processo relacional homem-sociedade e natureza.

Desse modo, considerando que a Caatinga é o único bioma exclusivamente brasileiro, com biodiversidade composta por fauna e flora peculiar, mas ainda é pouco explorada cientificamente, como também marginalizada no processo educativo, este trabalho objetiva analisar a percepção ambiental dos docentes da Escola Estadual de Ensino Médio Monsenhor Vieira, localizada no município de Patos, Estado da Paraíba.

\section{METODOLOGIA}

A pesquisa foi realizada com 10 professores da Escola Estadual de Ensino Médio Monsenhor Vieira, localizada no município de Patos, Estado da Paraíba, durante o mês julho de 
2016. O estudo caracterizou como sendo uma pesquisa de cunho qualitativo, onde utilizou-se os pressupostos teórico-metodológicos elementos da etnografia escolar, na forma demonstrada por Gil (2002).

Como instrumentos de coletas de dados utilizou-se um questionário estruturado, contendo questões conceituais sobre à biodiversidade e relativas ao bioma caatinga, com a finalidade de conhecer a percepção ambiental e aspectos relacionados a práticas pedagógicas do professor no campo da Educação ambiental. A escolha pela utilização de um questionário se deu, principalmente, pela facilidade de se descrever as características e por permitir uma melhor medição das variáveis dos grupos sociais estudados.

\section{RESULTADOS E DISCUSSÃO}

Na primeira pergunta do questionário, procurou-se saber dos professores que participaram da pesquisa, como eles definiriam a Caatinga, enquanto bioma.

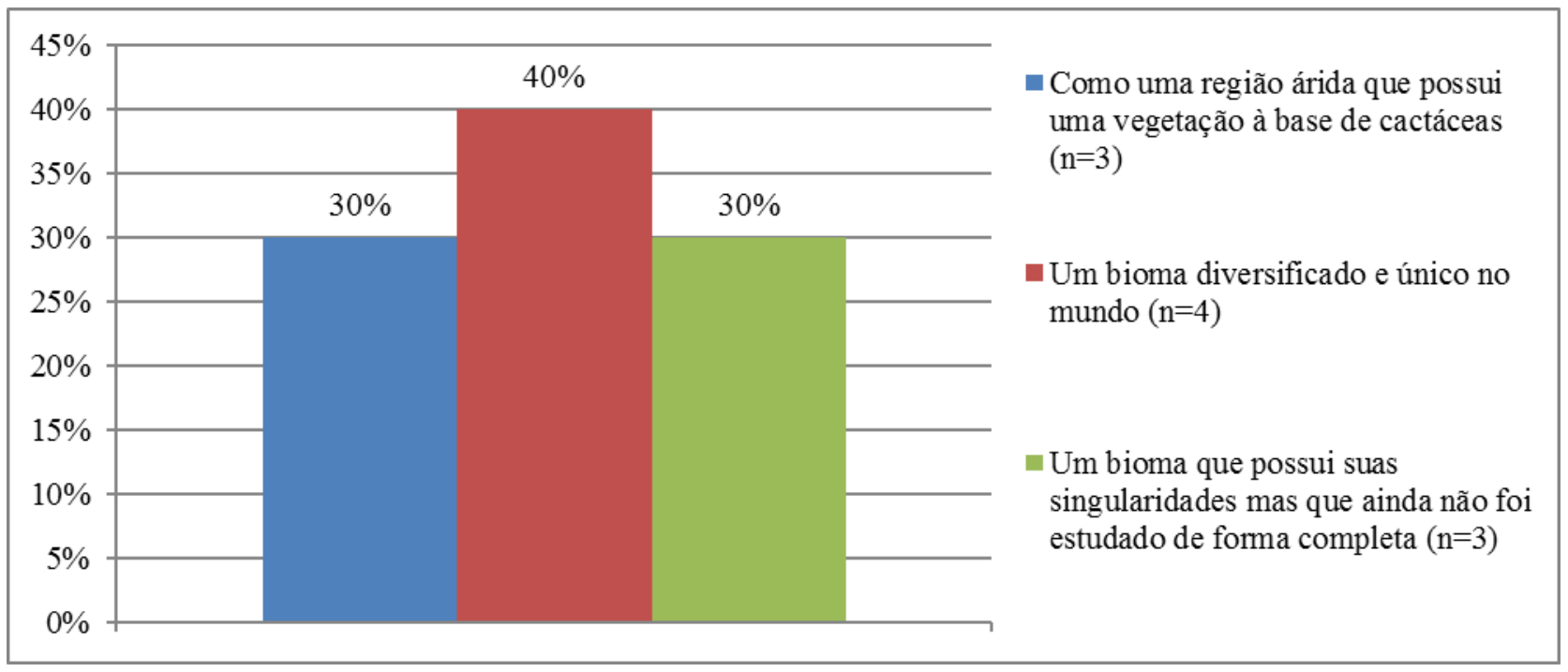

Figura 01. Gráfico com a distribuição dos participantes quanto à definição de Caatinga

Fonte: Elaborado pelos autores

De acordo com os dados apresentados na Figura 1, 30\% dos professores entrevistados definem a caatinga como sendo uma região árida que possui uma vegetação à base de cactáceas; $40 \%$ conceituam a Caatinga como sendo um bioma diversificado e único no mundo. E, os demais (30\%), como um bioma que possui suas singularidades, mas que ainda não foi estudado de forma completa. 
Duque (2004, p. 31) define a Caatinga como sendo "um conjunto de árvores e arbustos espontâneos, densos, baixos, retorcidos, leitosos, de aspecto seco, de folhas pequenas e caducas, no verão seco, para proteger a planta contra a desidratação pelo calor e pelo vento".

A Caatinga é o único bioma exclusivamente brasileiro. Por isso, grande parte do patrimônio biológico dessa região não é encontrada em outro lugar do planeta, além do nordeste do Brasil. Ela cobre quase todo o nordeste brasileiro, atingindo uma área de quase $10 \%$ do território nacional, abrangendo os Estados do Ceará, Rio Grande do Norte, Paraíba, Pernambuco, Sergipe, Alagoas e Bahia, sul e leste do Piauí e norte de Minas Gerais. Entretanto, essa vegetação única, constitui-se no terceiro bioma mais degradado ambientalmente, no Brasil, perdendo apenas para Floresta Atlântica e para o Cerrado (FERREIRA et al., 2007).

Ao longo de quase quinhentos anos, a Caatinga é explorada. De forma inconsciente, o homem utilizando-se de queimadas, devastou grandes extensões desse bioma, objetivando plantar pastagens e outras culturas, a exemplo do algodão, sem, contudo, preocupar-se com o desequilíbrio ecológico proveniente de suas ações impensadas (ROCHA et al., 2007).

Em ato continuo, indagou-se dos professores entrevistados quais as plantas típicas da Caatinga que apresentam um maior destaque. O Quadro 1 apresenta os resultados colhidos com esse questionamento.

Quadro 1 - Espécies Vegetais típicas da Caatinga citadas pelos docentes

\begin{tabular}{|c|c|c|}
\hline Famílias & Espécimes (Nome popular) & Percentual (\%) \\
\hline \multirow{3}{*}{ Anacardiaceae } & Braúna & $20 \%$ \\
\cline { 2 - 3 } Cactaceae & Umbuzeiro & $80 \%$ \\
\cline { 2 - 3 } & Palmatória & $10 \%$ \\
\cline { 2 - 3 } & Mandacaru & $30 \%$ \\
\hline Caesalpinioideae & Xique-xique & $60 \%$ \\
\cline { 2 - 3 } & Catingueira & $60 \%$ \\
\hline Burseraceae & Jucá & $100 \%$ \\
\hline Bromeliaceae & Imburama & $100 \%$ \\
\hline \multirow{2}{*}{ Mimosaceae } & Macabira & $60 \%$ \\
\cline { 2 - 3 } & Angico & $40 \%$ \\
\hline
\end{tabular}




\begin{tabular}{|c|c|c|}
\hline Euphorbiaceae & Pinhão & $30 \%$ \\
\hline Urticaceae & Urtiga & $100 \%$ \\
\hline Apocynaceae & Pereiro & $100 \%$ \\
\hline
\end{tabular}

Fonte: Elaborado pelos autores

Analisando o Quadro 1 verifica-se que o pereiro, a urtiga, o marmeleiro preto, o angico, a imburana, a catingueira, o xique-xique, a macambira e o umbuzeiro, encontram-se entre as espécies vegetais mais citadas pelos professores entrevistados na presente pesquisa. Algumas dessas espécies possuem uso medicinal tanto na etnobotânica quanto na etnoveterinária, como é o caso do pereiro, angico, pinhão, urtiga, jurema e catingueira (RODRIGUES et al., 2002).

Outras, porém, são utilizadas na alimentação tanto do homem, quanto de animais, com destaque para o umbuzeiro e o mandacaru, para a alimentação humana e o xique-xique, a palmatória, macambira, o marmeleiro para alimentação animal, principalmente, durante o período de estiagens. Já em relação ao uso da madeira, dentre as espécies vegetais da caatinga citadas pelos professores, destacam-se o pereiro, o angico e a imburana. No entanto, tem-se que reconhecer que a exploração desordenada desses recursos, principalmente, para a produção de carvão vegetal, tem comprometido a sustentabilidade do bioma Caatinga (ALBUQUERQUE et al., 2010).

Indagou-se ainda dos professores entrevistados, quais as espécies de animais nativos da Caatinga que eles mais conheciam. Os resultados obtidos foram condensados e apresentados no Quadro 2.

Quadro 2 - Animais típicos da Caatinga citados pelos docentes

\begin{tabular}{|c|c|c|}
\hline Classe & Espécies (Nome popular) & Percentual (\%) \\
\hline \multirow{3}{*}{ Mamífero } & Preá & $60 \%$ \\
\cline { 2 - 3 } & Tatu & $30 \%$ \\
\cline { 2 - 3 } & Gato do Mato (Maracajá) & $10 \%$ \\
\hline \multirow{2}{*}{ Repteis } & Cobra & $40 \%$ \\
\cline { 2 - 3 } & Camaleão & $20 \%$ \\
\cline { 2 - 3 } & Lagartixa & $40 \%$ \\
\hline \multirow{3}{*}{ Aves } & Carcará & $10 \%$ \\
\cline { 2 - 3 } & Rolinha & $20 \%$ \\
\cline { 2 - 3 } & Anum & $70 \%$ \\
\hline
\end{tabular}




\begin{tabular}{|l|c|c|}
\hline \multirow{3}{*}{ Insetos } & Abelha jandaíra & $20 \%$ \\
\cline { 2 - 3 } & Formiga & $50 \%$ \\
\cline { 2 - 3 } & Besouro do cão & $30 \%$ \\
\hline
\end{tabular}

Fonte: Elaborado pelos autores

Quando se analisa o Quadro 2, constata-se que segundo os professores entrevistados, as espécies de animais típicos da Caatinga que são por eles conhecidas são: o preá (mamífero), a cobra e a lagartixa (repteis), a rolinha (ave) e as formigas (insetos).

Alguns dos animais relacionados no Quadro 2, são com grande frequência abatidos e consumidos pelo sertanejo como forma de alimento, com destaque para preá, o tatu, o gato maracajá, o carcará, a rolinha e o anum. Este último, a espécie mais consumida é o anum branco. No que diz respeito à abelha jandaíra, popularmente conhecida como uma abelha sem ferrão, produz um excelente mel que além de ser consumido como alimento, possui uma utilização medicinal, sendo adicionado a algumas plantas medicinais a exemplo do mastruz, do limão, da laranja, da hortelã, da romã, bem como o e alho, principalmente, no sertão paraibano (ANDRADE et al., 2012).

Através do $4^{\circ}$ questionamento, indagou-se dos professores participantes, como eles caracterizam o Semiárido. Na Figura 2 encontram-se apresentados os dados relativos a esse questionamento.

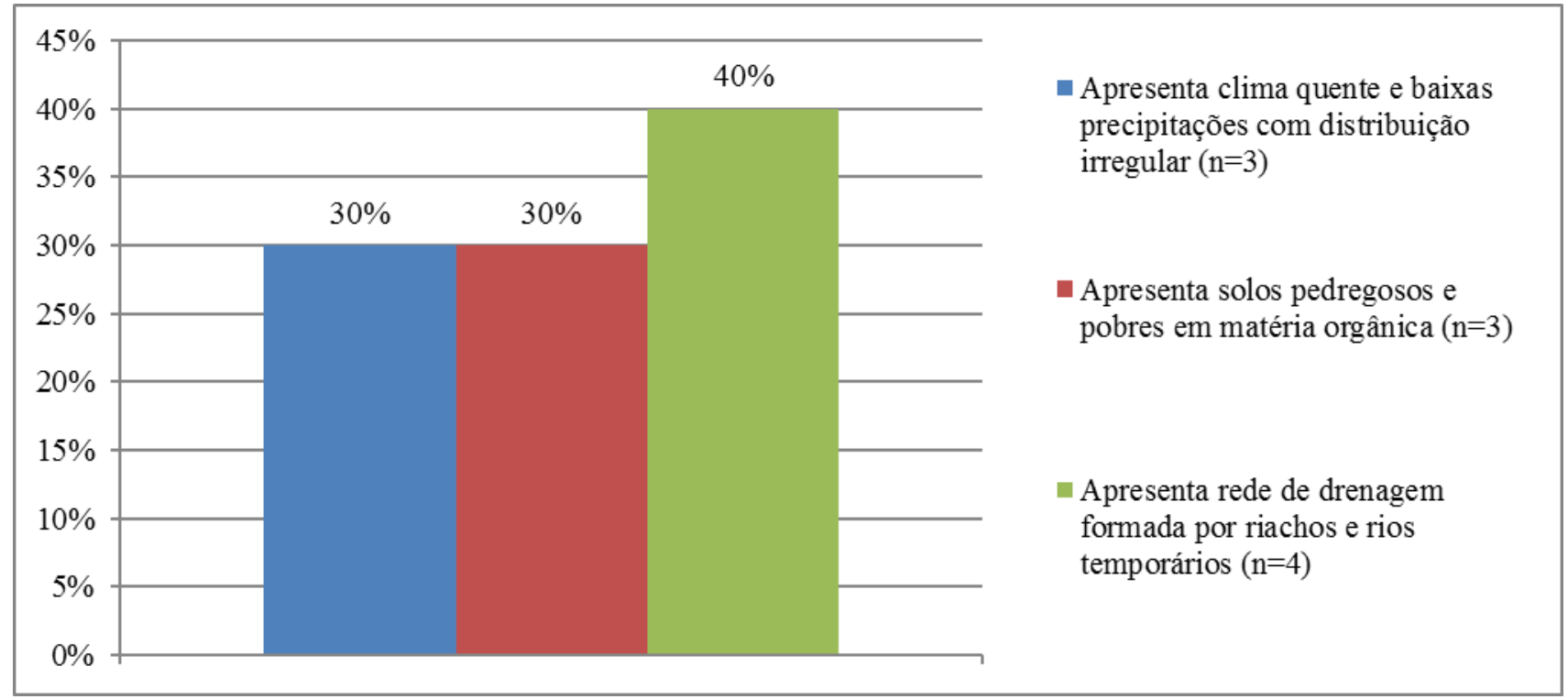

Figura 2. Gráfico com a distribuição dos participantes quanto ao fato de como eles caracterizam o Semiárido. Fonte: Elaborado pelos autores. 
Com base na Figura 2, verifica-se que 30\% dos professores entrevistados, caracterizam o Semiárido como sendo uma região que apresenta clima quente, possuindo também baixas precipitações distribuídas de forma irregular; $40 \%$ afirmaram que o Semiárido apresenta rede de drenagem formada por riachos e rios temporários, enquanto que os demais (30\%) declararam que tal região se caracteriza por apresentar solos pedregosos e pobres em matéria orgânica.

O semiárido nordestino caracteriza-se por possuir uma vegetação que apresenta um aspecto agressivo, havendo uma predominância de cactáceas colunares a exemplo do mandacaru e do facheiro, além de outros arbustos e árvores com espinhos. Nessa região, o solo é bastante pedregoso e pouco profundo. E, por isso, não consegue armazenar a água que cai, durante o período chuvoso (DUQUE, op. cit.).

Através do penúltimo questionamento perguntou-se aos professores participantes, se quando eles trabalham a educação ambiental se preocupam em contextualizar o ensino, estabelecendo uma correlação direta com o semiárido. Na Figura 3 encontram-se apresentados os dados colhidos com esse questionamento.

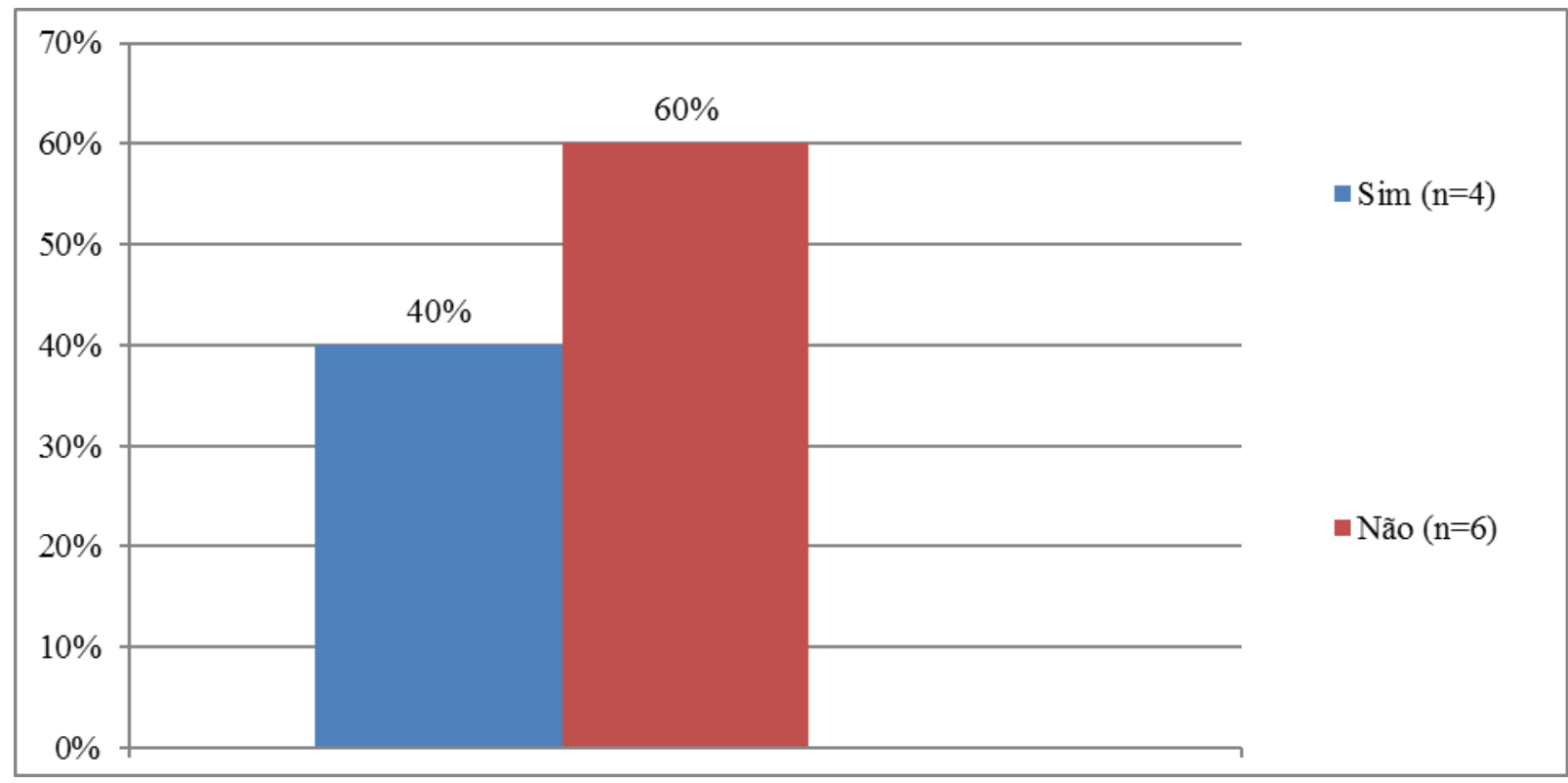

Figura 03. Gráfico com a distribuição dos participantes quanto ao fato de que quando trabalham a educação ambiental, preocupam-se ou não em contextualizar o ensino, fazendo uma correlação direta com o semiárido.

Fonte: Elaborado pelos autores

Analisando-se a Figura 3 verifica que somente $40 \%$ dos professores entrevistados quando trabalham a temática ambiental procuram estabelecer uma correlação direta com o semiárido, focalizando suas particularidades. No entanto, $60 \%$ dos entrevistados não fazem isto. 
De acordo com Almeida Filho (2007, p. 39), "toda vez que o professor for fazer a contextualização deve ter em mente que ela é necessária para criar imagens do campo que ele irá explorar", deixando "claro para o aluno que o saber é sempre mais amplo, que o conteúdo é sempre mais complexo do que aquilo que está sendo apresentado naquele momento".

A ideia central que se tem de 'contextualização' é a de procurar estabelecer uma correção entre o conteúdo apresentado em sala de aula com o 'mundo' [espaço/ambiente] no qual vive o aluno, de forma que este entenda melhor que está sendo transmitido. É importante ressaltar que o Estado brasileiro regulamentou a Educação Ambiental através da Lei no 9.795/1999. E essa lei, em seu art. $4^{\circ}$ aborda o ensino da Educação Ambiental de forma contextualizada.

Nesse sentido, Mello e Trajber (2007, p. 26) afirmam que os princípios contidos na lei acima citada, "buscam reforçar a contextualização da temática ambiental nas práticas sociais [...] com enfoques humanista, histórico, crítico, político, democrático, participativo, dialógico e cooperativo, respeitando o pluralismo de ideias e concepções pedagógicas”.

Desta forma, com base nas disposições contidas na Lei que instituiu a Política Nacional de Educação Ambiental, sempre que se abordar as questões ambientais no âmbito da sala de aula, deve-se contextualizar o ensino, focalizando a realidade local, de forma a proporcionar ao aluno uma maior visão sobre os problemas ambientais que existem em sua região, em sua localidade ou em seu município.

Por outro lado, a necessidade de se procurar inserir o Semiárido na temática ambiental quando de sua abordagem em sala de aula, reside no fato de que trata-seda região onde residem os alunos para dos quais, os entrevistados são professores. E seria por demais contributivo se o professor, ao abordar as questões ambientais em sala de aula procurasse estabelecer um paralelo com a realidade na qual encontra-se inserido o seu aluno.

\section{CONSIDERAÇÕES FINAIS}

$\mathrm{Na}$ atualidade, existe a necessidade de se promover uma maior discussão sobre as questões ambientais no contexto escolar, privilegiando-se a Educação Ambiental, levando-se em consideração seus objetivos, que primam pela construção de uma sociedade ecologicamente consciente e responsável com as futuras gerações.

Constatou-se que é consenso entre a maior parte dos entrevistados de que a Caatinga constitui um bioma único no mundo, possuindo suas singularidades, sendo formado por uma vegetação à base de cactáceas. Especificamente em relação ao Semiárido, os entrevistados possuem o entendimento de que se trata de uma região, que em razão das condições climáticas, é formada 
por riachos e rios temporários, apresentando ainda solos pedregosos e pobres em matéria orgânica. No entanto, a maioria dos professores enfrentam dificuldades em contextualizar o ensino, no que diz respeito a focalizar o semiárido nas discussões promovidas no contexto escolar. E, como tal temática não é abordada de forma ampla, vem contribuindo para limitar o conhecimento sobre a região semiárida, apresentado pelos alunos na visão da maioria dos professores entrevistados.

Isto fato demonstra a necessidade de uma maior capacitação por parte dos professores em torno das questões ambientais, bem como a necessidade de uma definição de novas metodologias que proporcionem uma maior aquisição de conhecimento por parte dos alunos, proporcionando, assim, uma aprendizagem significativa e a formação de cidadãos ecologicamente conscientes.

Em resumo, existe a necessidade de se investir na formação continuada destes professores, de maneira que sejam trabalhados aspectos de instrumentação de seus conhecimentos, de forma a desenvolver cada vez mais a Educação Ambiental para o desenvolvimento sustentável de Semiárido nordestino.

\section{REFERÊNCIAS}

ABÍLIO, F. J. P.; FLORENTINO, H. S. Educação Ambiental e o Ensino de Geografia na Educação básica. In: ABÍLIO, F. J. P.; SATO, M. (Org.). Educação ambiental: do currículo da educação básica às experiências educativas no contexto do semiárido paraibano. João Pessoa: EDUFPB, 2011, 278p.

ALBUQUERQUE, U. P. [ et al.]. Caatinga: biodiversidade e qualidade de vida. Bauru-SP: Canal, 2010.

ALMEIDA FILHO, G. P. Transposição didática: por onde começar. São Paulo: Cortez, 2007, $322 p$.

ANDRADE, S. E. O. et al. Estudo etnoveterinário de plantas medicinais na comunidade Várzea Comprida dos Oliveiras, Pombal, Paraíba, Brasil. Revista Verde de Agroecologia e Desenvolvimento Sustentável, v. 7, n. 2, p 193-198, abr-jun, 2012.

ARAUJO, C. S. F.; SOUSA, A. N. Estudo do processo de desertificação na Caatinga: uma proposta de educação ambiental. Ciências da Educação. Bauru, v. 17, n. 4, 2011.

CASTELLETTI, C. H. M.; SANTOS, A. M. M.; TABARELLI, M.; SILVA, J. M. C. Quanto ainda resta da Caatinga? Uma estimativa preliminar. In: LEAL, I. R.; TABARELLI, M.; SILVA, J. M. C. (eds.). Ecologia e conservação da caatinga. Recife: EDUFPE, 2005.

DUQUE, G. Solo e água no polígono das secas. Fortaleza: Banco do Nordeste do Brasil, 2004.

FERREIRA, L. M. R. [et al] . Análise fitossociológica comparativa de duas áreas serranas de caatinga no cariri paraibano. VIII Congresso de Ecologia do Brasil, 23 a 28 de Setembro de 2007. Anais..., Caxambu-MG. 
GIL, A. C. Como elaborar projetos de pesquisa. 10 ed. São Paulo: Atlas, 2002.

MELO, S. S. de; TRAJBER, R. Vamos cuidar do Brasil: conceitos e práticas em educação ambiental na escola. Brasília: Ministério da Educação, Coordenação Geral de Educação Ambiental: Ministério do Meio Ambiente, Departamento de Educação Ambiental: UNESCO, 2007, 432p.

ROCHA, W. F. Levantamento da cobertura vegetal e do uso do solo do Bioma Caatinga. XIII Simpósio Brasileiro de Sensoriamento Remoto, Florianópolis, Brasil, 21-26 abril 2007, INPE. Anais..., p. 2629-2636.

RODRIGUES, L. A. et al. Espécies vegetais nativas usadas pela população local em Luminárias, MG. Lavras: UFLA, 2002. 34 p. (Boletim Agropecuário, 52).

SILVA, T. S.; CÂNDIDO, G. A.; FREIRE, E. M. X. Conceitos, percepções e estratégias para conservação de uma estação ecológica da caatinga nordestina por populações do seu entorno. Sociedade \& Natureza, v. 21, n. 2, p. 23-37, ago., 2009.

Recebido em: 14/08/2016

Aceito para publicação em: 01/10/2016 